\title{
Технологии и оборудование компании "Крисмас+": готовые решения для химического анализа
}

\author{
А. Г. Муравьёв, К.х.Н., М. А. Кузьмин, \\ ЗАО «Крисмас+», Санкт-Петербург \\ muravyov@christmas-plus.ru
}

\begin{abstract}
Представлен обзор уникальных технологий и оборудования, которые разрабатывает, производит и реализует на российском рынке и в странах бывшего СССР отечественная компания ЗАО "Крисмас+». Продукция компании представляет собой готовые решения для аналитиков, работающих во многих секторах производственной, научной и учебной деятельности. Запатентованные технические решения, зарегистрированные свыше 20 лет назад торговые марки, внесенные в федеральные реестры методики и средства измерений - все это характеризует высокий научно-технический уровень выпускаемой продукции и способ ведения наукоемкого бизнеса. Прочный экономический базис вселяет уверенность в завтрашнем дне современной компании, производство которой полностью локализовано в России.
\end{abstract}

Основанная в 1995 году химиками-аналитиками из СанктПетербурга, компания ЗАО "Крисмас+» сегодня является головной в группе компаний "Крисмас".

ЗАО "Крисмас+» производит различные портативные аналитические системы, позволяющие проводить химические экспресс-анализы как в полевых, так и в лабораторных условиях. Широкая линейка продукции включает сигнальные тест-системы, измерительные тест-комплекты для количественных и полуколичественных анализов, переносные комплектные мини-лаборатории для применения в полевых условиях или в помещениях [1]. Система менеджмента качества компаний, входящих в ГК "Крисмас", сертифицирована на соответствие требованиям международного стандарта ISO 9001.

Разработками и продукцией компании активно пользуются государственные службы: Роспотребнадзор (Госсанэпиднадзор), подразделения МЧС, производственные лаборатории, службы экологического контроля и мониторинга, образовательные учреждения и многие другие.

Быстрые химические анализы требуются во многих отраслях. Это анализ воды (питьевой, сточной, воды из природных водоемов и грунтовых вод, котловой воды энергосистем), образцов почвы, санитарный анализ продуктов питания, экологический контроль воздуха, мониторинг газообразных отходов промышленности и т.д.
Продукция основана на технологиях анализа, которые, благодаря продуманным алгоритмам анализа, готовым методикам и доходчивым руководствам может использовать не только специалист, но и человек со средним образованием после небольшого тренинга. Все операции четко и доступно описаны в руководствах по эксплуатации или инструкциях, их можно быстро понять и освоить. Изделия комплектуются готовыми растворами, реагентами, посудой, необходимыми принадлежностями. Если какой-то раствор не может храниться долго, предоставляется необходимый инструментарий, чтобы потребитель смог приготовить его на месте. Все расходные материалы и реагенты отечественного производства и легко восполняются.

Все изделия сертифицированы в зависимости от области применения в различных отечественных системах обязательной и добровольной сертификации. В их число входят:

- обязательные метрологические сертификационные испытания с целью внесения в Государственный реестр средств измерений (ГРСИ) и в Федеральный реестр методик измерений (МИ);

- система добровольной сертификации аварийно-спасательных средств Мчс России;

- система добровольной сертификации продукции и производств общепромышленного назначения при Российском морском регистре судоходства; 
- система добровольной сертификации учебных изделий "Учсерт" при Российской системе образования;

- различные ведомственные системы апробации и одобрения отдельных видов продукции, рекомендации методических организаций.

Специалисты компании серьезно подходят к стандартизации измерительных средств и используемых в них методик в соответствии с нормативно-техническими документами (НТД) Российской Федерации. Во многих изделиях применены химико-аналитические методики, уже аттестованные и внесенные в действующие НТД. Когда требуется их адаптация к портативным системам - вносятся допустимые изменения в перечень используемых средств измерений и оборудования, алгоритм, диапазон рабочих температур и т.п., после чего методика заново проходит аттестацию. Если не удается использовать нормативные методики, специалисты компании разрабатывают собственные, оригинальные, которые проходят аттестацию и получают статус полевых методик. Например, успешно модифицировано более 20 нормативных методик анализа питьевой, природной и котловой воды. Кроме того, нашей компанией разработано девять оригинальных методиканализа воды, которые внесены в Федеральный реестр МИ и признаны пригодными для применения в составе различных изделий тест-комплектов, полевых и ранцевых мини-лабораторий.

Унификация аналитических систем и комплектующих лежит в основе стандартизации продукции ЗАО «Крисмас+". Для определения различных компонентов, как правило, применяют унифицированные аналитические методы, то есть сходные по основным типовым операциям и оснащению. Реагенты и растворы готовятся по более или менее одинаковой схеме, проходят единую процедуру контроля качества. Компоненты наборов компактные, легкие, эргономичные и удобные в использовании. Флаконы для реагентов изготовлены из полипропилена, фторопласта, полиэтилентерефталата (ПЭТ) и т. п. - они не бьются, удобно открываются, химически инертны и герметичны. Реагенты и инструменты (пипетки, пробирки и т.п.) уложены компактными блоками, в каждом - индивидуальный тест-комплект для определения одного или нескольких аналогичных веществ. Содержимое блоков помещается в специальный ложемент, затем блоки складируют в жестких, удобных для хранения, переноски и транспортирования укладках-контейнерах.

Компания производит средства для экспресс-анализов разных уровней сложности и точности. К наиболее простым относятся сигнальные тест-системы, дающие ответ "да" или "нет" на вопрос: присутствует ли определяемое вещество в концентрации выше порогового значения. Такие изделия не требуют сертификации. Наиболее информативны средства для количественного экспресс-анализа, основанные на аттестованных методиках выполнения измерений. Они обычно снабжаются портативными измерительными приборами в дополнение к химико-аналитическим рецептурам. Промежуточное положение занимают средства полуколичественного анализа, когда не требуется точное значение определяемого параметра, а достаточно лишь приблизительной его оценки. Эти средства используют вместо измерительных приборов визуальные цветовые шкалы.

\section{АНАЛИЗ ВОЗДУХА И ГАЗОВ}

Анализ воздуха и промышленных газовых выбросов - та область, где гораздо проще и удобнее использовать портативные средства, чем проводить измерения в лабораторных условиях. Поэтому на рынке присутствует большое количество портативных средств самых разных производителей, российских и зарубежных. Чаще всего используются индикаторные трубки и индикаторные элементы, которые в середине прошлого века разрабатывали несколько научных школ и коллективов в СССР.

Индикаторные трубки модели ТИ-[ИК-К], производимые компанией ЗАО «Крисмас+», - универсальный инструментарий для химического экспресс-контроля воздуха и промышленных газовых выбросов (рис. 1) . Серия включает 52 модификации различных наименований, все внесены в Государственный реестр средств измерений (ГРСИ), для них есть единое руководство по эксплуатации [2]. По диапазонам определяемых концентраций трубки делятся на три категории: для контроля чистоты воздуха при концентрациях существенно ниже ПДК, для контроля возможного превышения ПДК, для мониторинга после аварийных ситуаций (когда ПДК превышается в несколько раз и более).

Комплектные мини-экспресс-лаборатории и газоопределители на основе индикаторных трубок предназначены для определения целого ряда компонентов.

Мини-экспресс-лаборатория «Пчёлка-Р» (имеет две модификации - в кейсе и в сумке) занимает одно из ведущих мест среди комплектов средств измерений, которые используют службы ГО и ЧС, центры гигиены и эпидемиологии и т.п. Она позволяет проводить экспресс-контроль химического загрязнения воздуха и промышленныхгазовых выбросов, воды, почвы, сыпучих

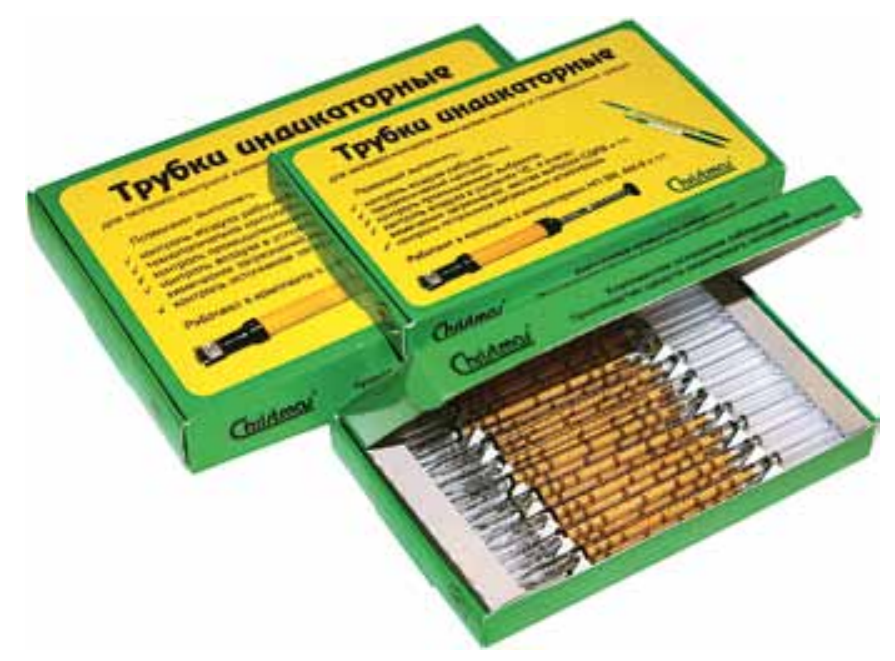

Puc.1. Индикаторные трубки ТИ-[ИК-К] в упаковке 


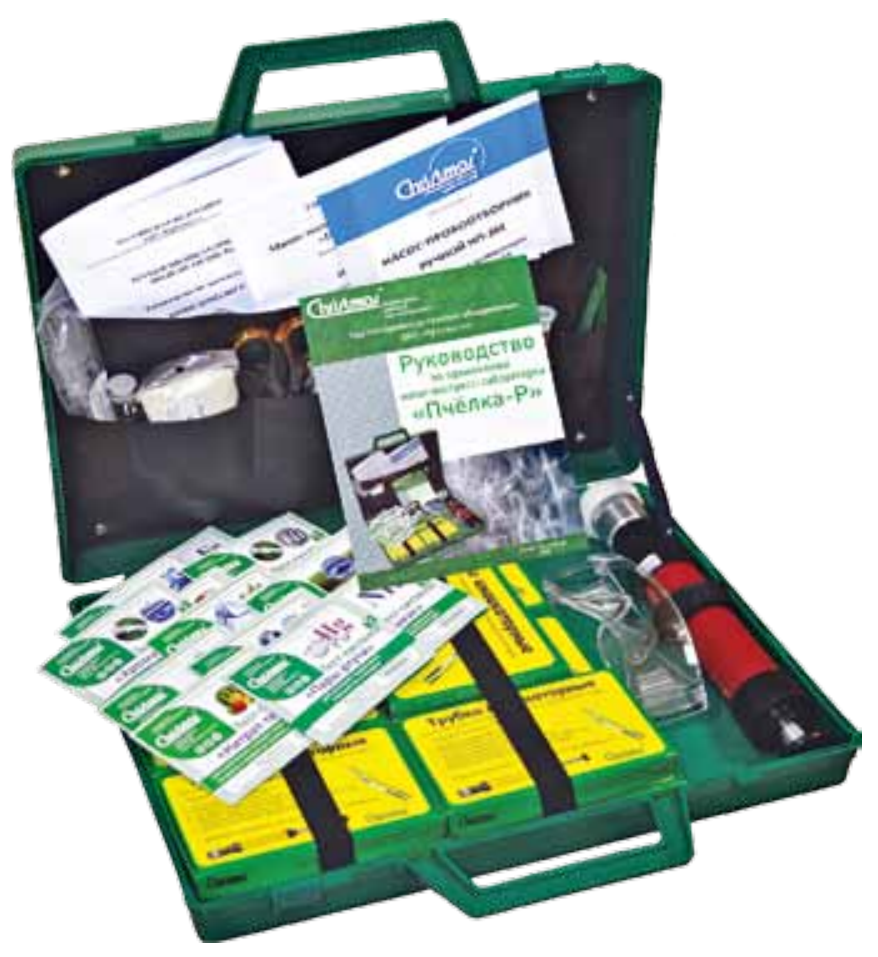

Puc. 2. Мини-экспресс-лаборатория «Пчёлка-Р» в контейнереукладке типа "кейс»

сред, определять содержание нитратов в продуктах питания и др. Мини-лаборатория содержит 10 видов индикаторных трубок и 10 тест-систем. В воздухе определяются опасные соединения: пары ртути, сероводород, оксид углерода, хлор и т.п. В воде и почве измеряется содержание активного хлора, нитратов, нитритов, железа, сульфид-ионов, водородный показатель (рН).

Для отбора проб воздуха и газов совместно с индикаторными трубками применяют аспираторы серии НП-ЗМ. Они входят в комплект мини-экспресс-лабораторий «Пчёлка-Р» (рис. 2). Благодаря металлической основе производимые ныне аспираторы чрезвычайно долговечны; требуется только периодическая замена резиновых частей, смазка и поверка. Недавно налажено серийное производство аспираторов новой серии НП-4, меньших по габаритам и весу. Конструктивные решения для обоих аспираторов защищены патентами РФ.

Аспираторы НП-ЗМ (рис. 3) имеют два значения отбираемого объема - 50 и 100 мл, а НП-4 - только 100 мл. Для наших индикаторных трубок практически всегда используются объемы,

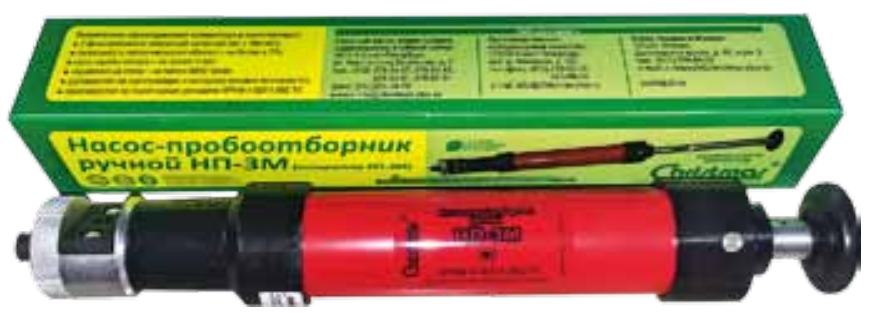

Puc. 3. Acnupamop НП-3M кратные 100 мл. Ежегодно сервисная служба ЗАО «Крисмас+» совместно с ФБУ «Тест-Санкт-Петербург» поводит периодическую проверку точности аспираторов (поверку), по итогам которой выдается соответствующее свидетельство единого образца.

Каспираторам предлагается ряд аксессуаров. Пробоотборный зонд ЗП-ГХКМ предназначен для отбора газообразных проб в труднодоступных местах - воздуховодах, колодцах, цистернах и т.п. Зонд имеет измерители температуры, давления и влажности. Эти данные важны для точности измерений: температура и давление содержатся в формуле расчета концентраций определяемого газа. Полиэтиленовая газовая емкость ЕПГ, объемом до 10 л, используется для кратковременного хранения газовых образцов и их доставки к месту последующего анализа. Для удобства она имеет два штуцера с зажимами и застежку-молнию. Измеритель прокачиваемого объема ИО-2 применяют для проверки точности аспираторов, также для контроля точности градуировки мерной посуды.

Также компания производит тест-системы для химического анализа воздуха - наиболее простые и экономичные средства сигнального или полуколичественного химического анализа, сочетающие максимальные экспрессность, простоту применения, наглядность и достоверность результата, доходчивость и лаконичность инструкции.

\section{АНАЛИЗ ВОДЫ}

Пробы воды, в отличие от воздуха и газов, гораздо чаще анализируют в лабораториях, чем в полевых условиях. Процедуры анализа воды регламентированы множеством нормативных документов, которым зарубежные анализаторы часто не соответствуют. Поэтому потребность рынка в отечественных средствах экспресс-контроля воды весьма высока.

Многие методики, разработанные и аттестованные для анализов в помещениях, были модифицированы специалистами ЗАО "Крисмас+» для применения в полевых условиях [3]. Ключевыми моментами при переработке методик являлась легкость пробоподготовки и аналитической процедуры, унификация методов, простота визуализации и интерпретации результатов, возможность проведения анализов в самых разных условиях. В большинстве методик расширен диапазон рабочих температур, значений атмосферного давления и влажности воздуха. Средства количественного анализа воды компании «Крисмас+» можно использовать при температурах от 10 до $35^{\circ} \mathrm{C}$, а сигнальные тест-системы - от 5 до $50^{\circ} \mathrm{C}$. Давление и влажность нормируются лишь для ряда методик, где используются фотоэлектроколориметры.

Аналитические системы "Крисмас+» - портативные тесткомплекты, полевые и настольные лаборатории, мини-экспресслаборатории - позволяют количественно определять в водных пробах более 60 различных веществ, измерять такие важные показатели, какрН, общую минерализацию, окисляемость, мутность, жесткостьи и.п. (рис. 4).

Суть колориметрического анализа состоит в визуальном сравнении цвета или интенсивности окраски раствора со шкалой. 



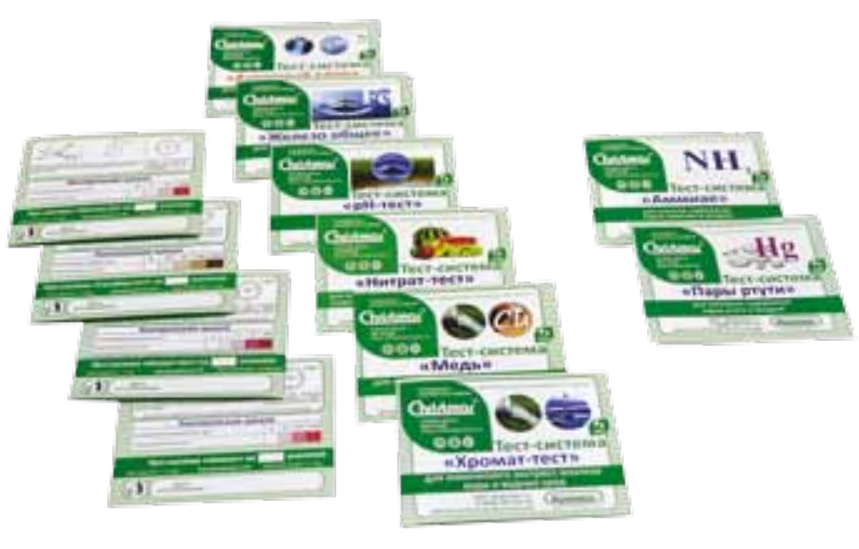

Puc. 4. Тест-системы для химического анализа воздуха, воды и водных сред

Средства титриметрического анализа этого класса комплектуются полимерными экспресс-пипетками, деления которых, тем не менее, достаточно точно соответствуют указанным объемам

Тест-комплекты для количественного анализа методом колориметрии содержат полевой фотоколориметр "Экотест-2020", который компания производит совместно с НПП "Эконикс". Прибор внесен в Государственный реестр средств измерений Он имеет восемь светодиодных источников света с различными длинами волн от 400 до 850 нм и запрограммирован под унифицированные методики выполнения измерений на основе тесткомплектов и полевых лабораторий от ЗАО «Крисмас+».

Портативные лаборатории контроля воды и водных вытяжек семейства НКВ служат для исследования образцов воды по многим показателям. Их основные пользователи - экологические службы, подразделения центров гигиены и эпидемиологии. Лаборатории НКВ определяют не менее 18 показателей, в ряду которых жесткость, окисляемость, общая минерализация, рН, цветность, мутность, вкус, запах, содержание ряда катионов и анионов, остаточный хлор и др. Они полностью автономны: анализы можно проводить как в помещениях так и в полевых условиях. Существуют ранцевые модификации для экспедиций. Лаборатории НКВ защищены патентом Российской Федерации. Основные использованные методики аттестованы и внесены в Федеральный реестр методик выполнения измерений

Комплектные лаборатории НКВ непрерывно совершенствуются. Сейчас наибольшей популярностью пользуется настольная модификация НКВ-12 (рис. 5). Изначально ее конструкция задумывалась для лабораторий инженерных войск. Она выполнена в виде раскрывающегося кейса-чемодана, который в открытом виде представляет собой профессиональное рабочее место оператора, превращаясь в настоящую лабораторию. Качество воды и состав водных вытяжек определяется не менее чем по 24 показателям. НКВ-12 выпускается в восьми модификациях, в том числе: "Вода природная и водоподготовка", "Водоснабжение и водоотведение", "Воды агрессивные грунтовые", "Вода расфасованная".

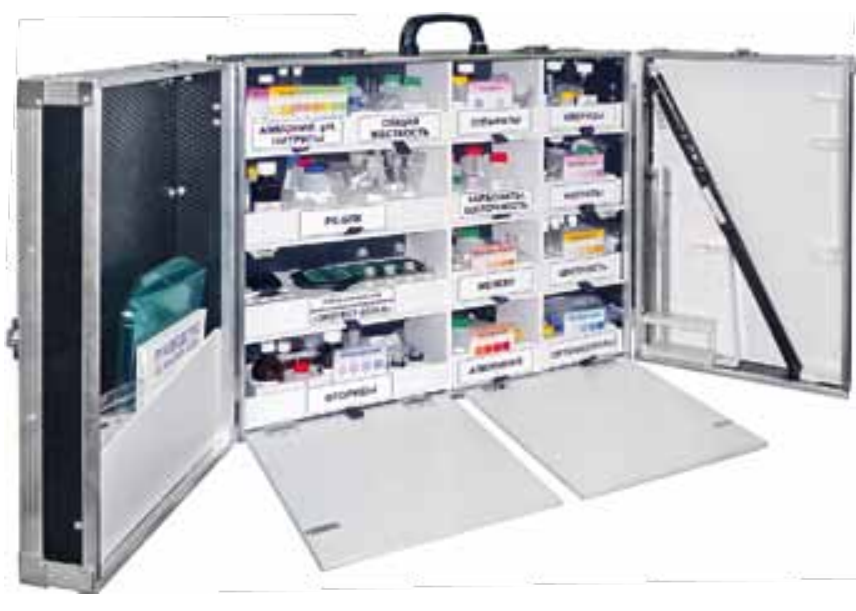

Puc. 5. Hастольная паборатория анализа воды HКВ-12

\section{АНАЛИЗ ПРОБ КОТЛОВОЙ ВОДЫ И ВОДОПОДГОТОВКА}

Анализ котловой воды имеет ряд особенностей. Это, прежде всего, сложность отбора проб и высокая чувствительность анализа. Согласно действующим нормативно-техническим документам, для анализов котловой воды по отдельным компонентам требуется более высокая чувствительность, чем для питьевой и природной. Кроме того, в энергетическом котловом оборудовании необходимо использовать только специально обработанную воду, соответствующую определенным стандартам.

Водно-химическая котловая экспресс-лаборатория ВХЭЛ применяется для химико-аналитического контроля содержимого водных и паровых котлов в больших и малых котельных, ТЭЦ, тепловых сетях, различных котлоагрегатах [4]. Контроль ведется прежде всего для проверки соответствия параметров качества воды и пара нормативным значениям. С применением ВХЭЛ могут отбираться и анализироваться разнообразные среды (потоки) из точек отбора, встречающихся на большинстве производственных площадок (воды после деаэраторов, после подпиточного насоса, сетевой воды перед котлом и после сетевого насоса, конденсата пара и т. п.).

Главный модуль ВХЭЛ сделан в виде переносного кейса массой около 20 кг. Модификации ВХЭЛ-2 и ВХЭЛ-3 включают портативный кондуктометр "Эксперт-002-2" для определения удельной электрической проводимости и общего содержания солей.

Помимо комплектных лабораторий, выпускаются индивидуальные тест-комплекты для анализа всех параметров котловой воды, указанных выше, а также перманганатной окисляемости, содержания в воде примесей нефтепродуктов и масел. Из-за сложности отбора проб и необходимости кондиционирования были разработаны вспомогательные изделия - набор для отбора и переноски проб, комплект средств для приготовления очищенной воды. Они, как правило, приобретаются вместе с лабораториями ВХЭЛ (рис. 6). 


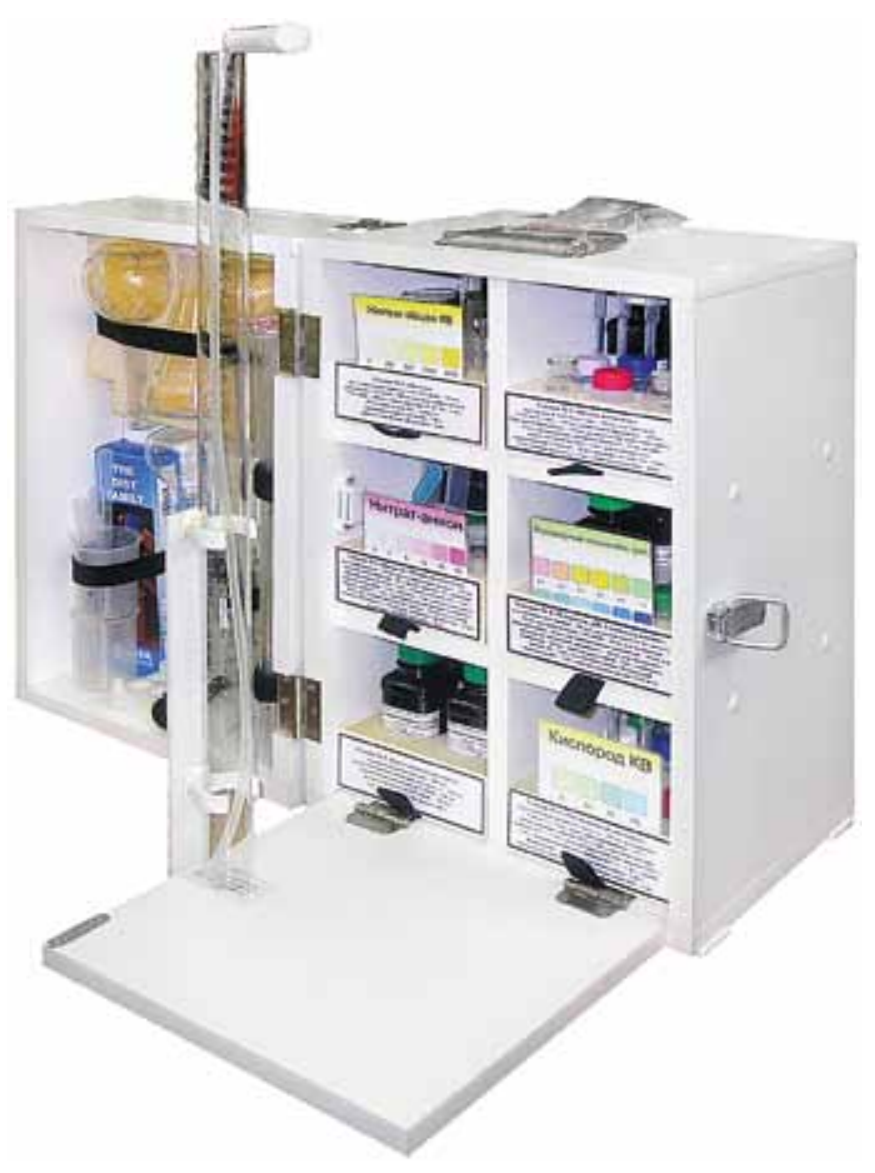

Puc. 6. Водно-химическая котловая экспресс-лаборатория ВХЭЛ, главный модуль

Судовая водно-химическая экспресс-лаборатория СЛКВ, выполненная аналогично ВХЭЛ, применяется для экспрессконтроля рабочих показателей технической воды, используемой при эксплуатации судов (в силовых установках, установках водоочистки и водоподготовки).

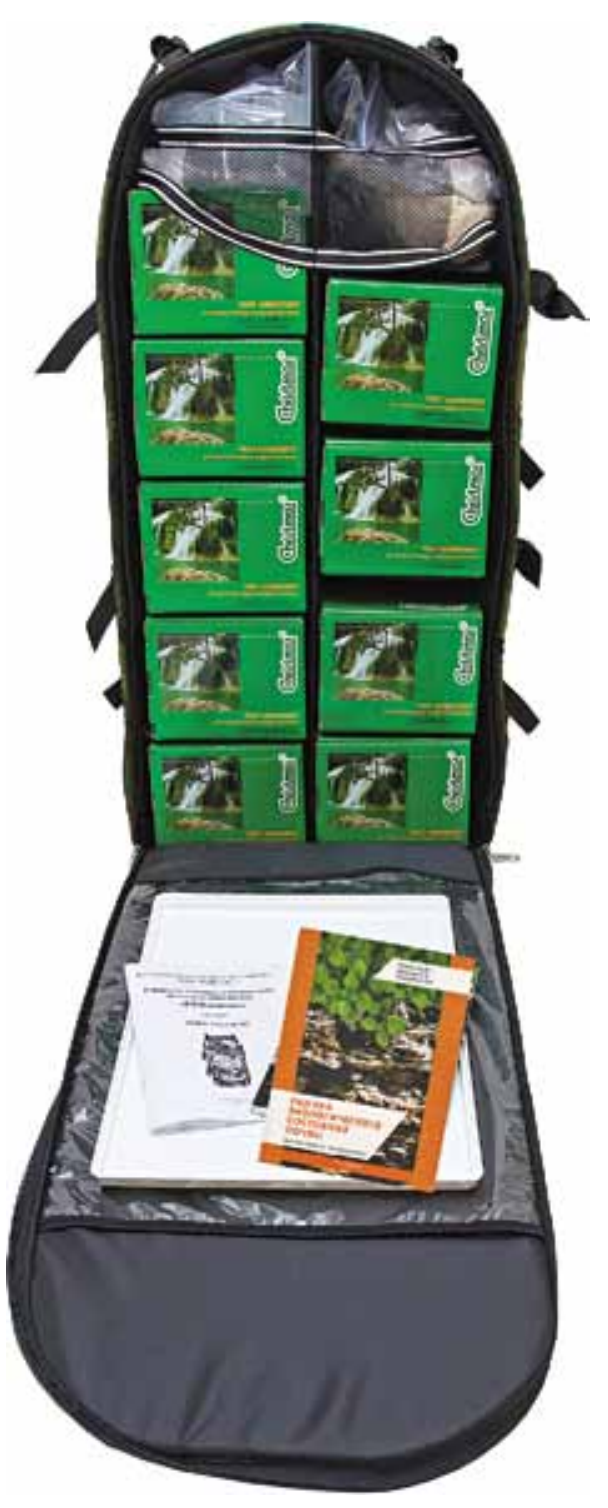

Puc. 7. Ранцевая почвенная лаборатория РПЛ

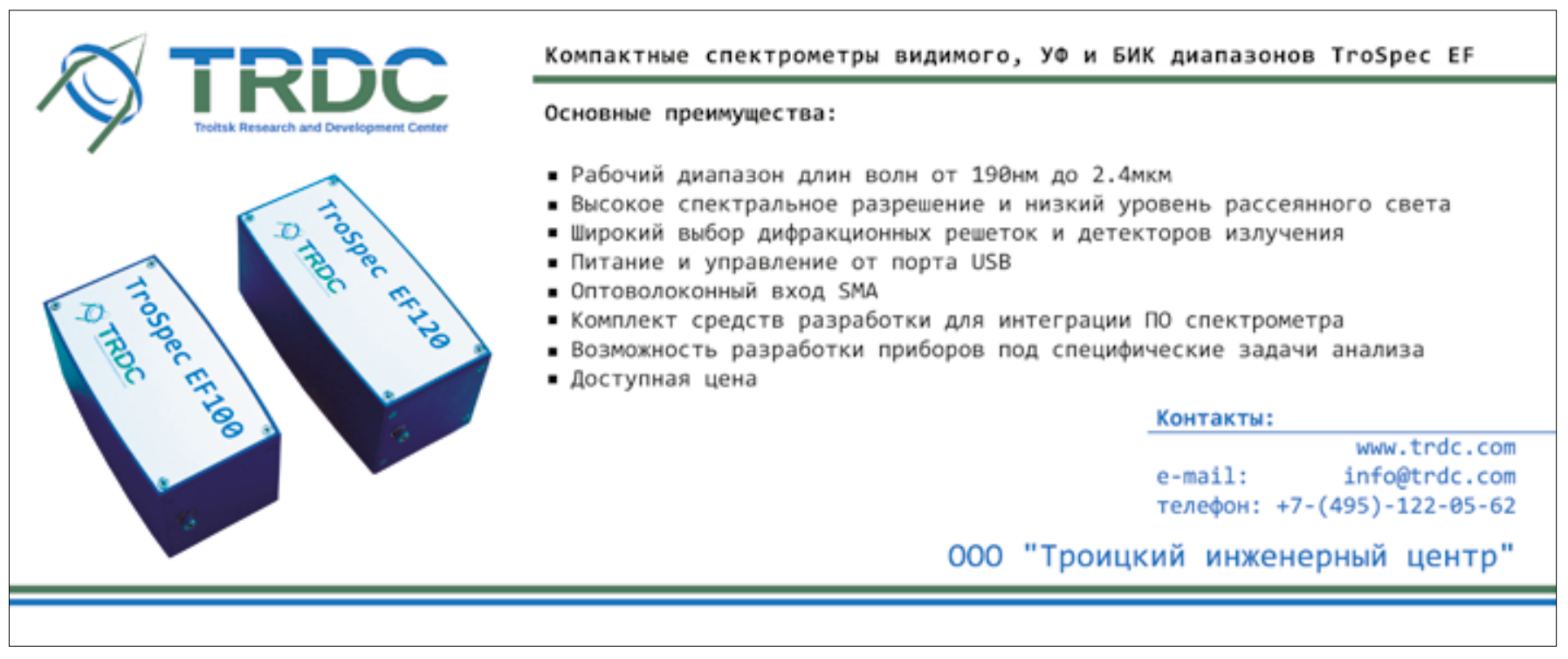




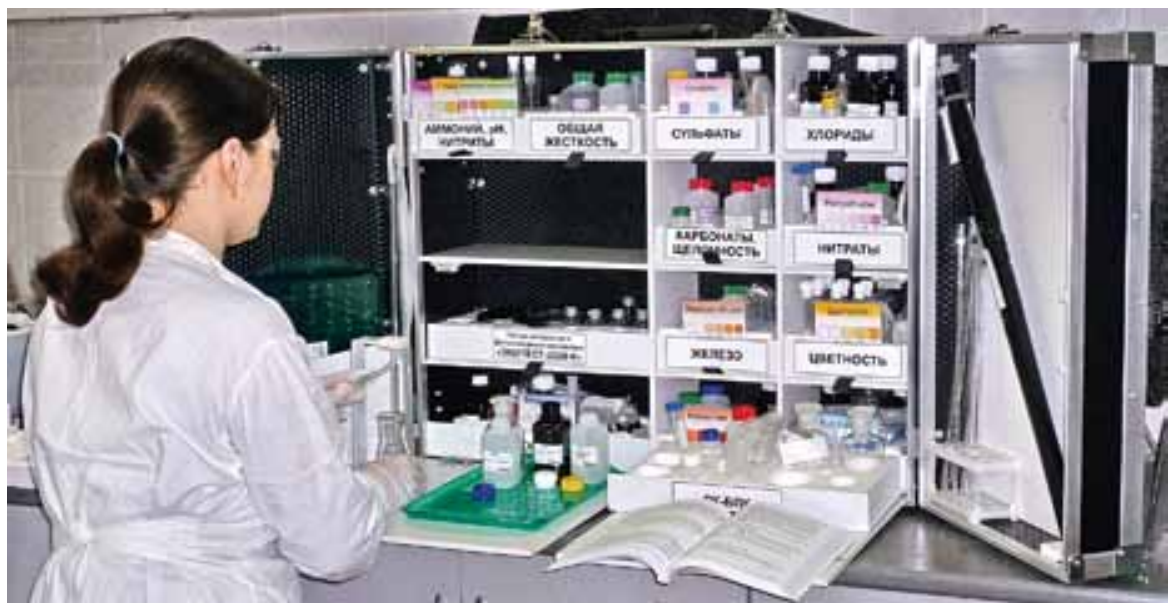

Puc. 8. Настольная почвенная паборатория НПЛ

для фотоколориметрирования с прибором "Экотест-2020", кондуктометр и рН-метр [5] (рис.7).

Настольная почвенная лаборатория модели НПЛ отличается универсальной укладкой. Ее можно применять как в стационарной лаборатории, так и в условиях базового лагеря. Она выполнена в виде раскрывающегося кейса, который в открытом виде представляет собой профессиональное рабочее место оператора. Лаборатория содержит полный комплект для анализа почвы по 14 показателям, включая набор для приготовления вытяжек, рН-метр и кондуктометр (рис. 8).

\section{АНАЛИЗ ОБРАЗЦОВ ПОЧВЫ И ПОЧВЕННЫХ ВЫТЯЖЕК}

Химический анализ почвенных вытяжек в целом аналогичен анализу воды, но представляет собой более трудоемкий процесс. Необходимо предварительно провести отбор проб, пробоподготовку, приготовление вытяжек. Каждый из этапов, включая саму процедуру анализа, регламентируется целым рядом соответствующих нормативно-технических документов. Нормативные методики анализа почв существенно отличаются от методик анализа воды, поэтому для работы с почвами и почвенными вытяжками компания разработала специальные серии средств экспресс-анализа. Хотя в отдельных случаях почвенные вытяжки можно анализировать и средствами, разработанными для работы с водой.

В сфере портативных средств для химического анализа почвы продукция ЗАО "Крисмас+» остается вне конкуренции. Аналогичное оборудование других производителей на российском рынке не представлено.

Для анализа почвы компания "Крисмас+» предлагает индивидуальные измерительные комплекты и комплектные мини-лаборатории. Можно определять кислотность, влажность, катионнообменную емкость почвы, содержание в почве главных катионов и анионов, фенолов и нефтепродуктов и т. п. Методики, используемые данными изделиями, соответствуют действующей нормативно-технической документации по анализу почв.

Ранцевая почвенная лаборатория модели РПл выполнена в виде рюкзака объемом 70 л и весом не более 20 кг. Базовая модификация содержит все необходимое для комплексного исследования почвы по 11 основным показателям: тест-комплекты, тест-системы, набор посуды и реактивов для приготовления водных и солевых почвенных вытяжек, весы с разновесами, почвенный термометр, просеивающее сито и ряд других инструментов. Расширенные модификации этих лабораторий могут содержать набор-укладку

\section{САНИТАРНО-ПИЩЕВОЙ АНАЛИЗ}

В сферу санитарно-пищевого анализа входит оценка доброкачественности пищевых продуктов и готовых блюд, а также санитарного состояния пищевых объектов, прежде всего предприятий общественного питания, и имеющегося в них столового инвентаря. Исключительная важность санитарнопищевого контроля очевидна. Несмотря на это, на российском рынке наблюдается острый дефицит средств экспресс-оценки качества и пригодности продуктов питания и готовых блюд, а также санитарно-технического состояния объектов питания и приготовления пищи.

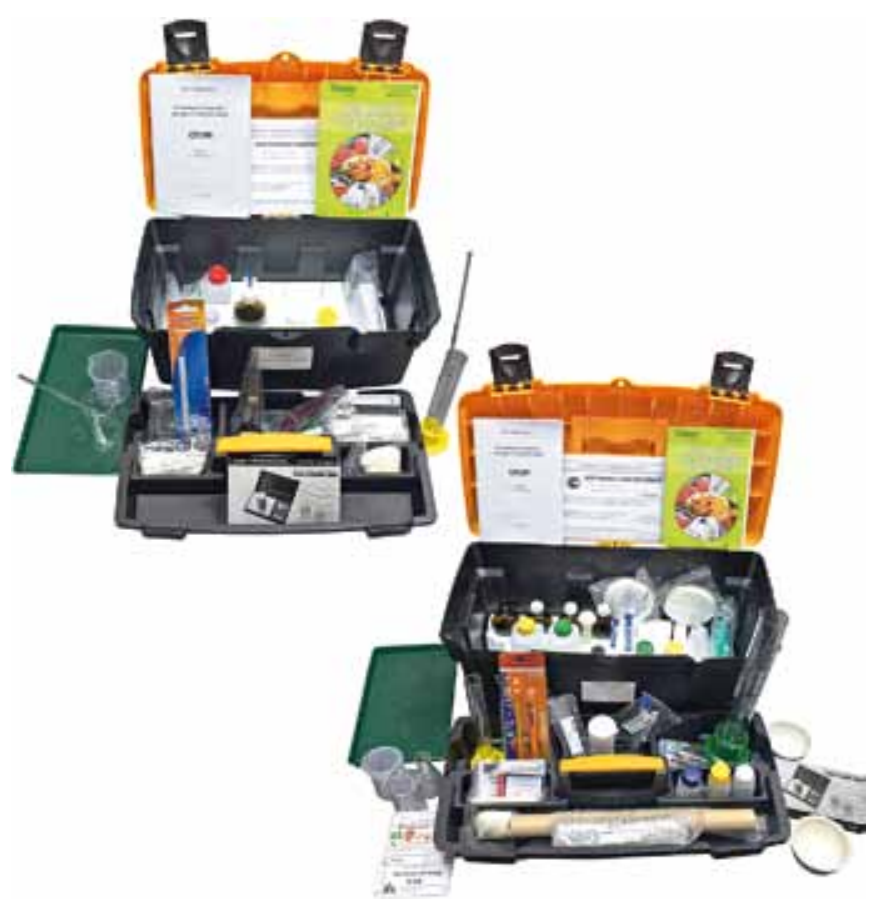

Puc. 9. Санитарно-пищевая экспресс-лаборатория СПЭЛ 
В нормативно-технической документации по санитарнопищевому анализу преобладают тестовые методы, не требующие точных количественных определений. Поэтому предлагаемые компанией аналитические средства основаны на простых тест-комплектах и тестовых системах. В то же время количество отдельных показателей, составляющих анализ качества продуктов питания и санитарного состояния объектов, весьма большое.

Санитарно-пищевая экспресс-лаборатория Спэл, разработанная в соответствии с требованиями действующих нормативных документов, позволяет проводить анализ продуктов питания и пищевого сырья, а также оценку санитарного состояния пищевых объектов [6]. Все процедуры проводятся непосредственно на пищевом объекте, без доставки образцов в лабораторию. Исследования проводятся полуколичественными и качественными (сигнальными) химическими методами с использованием унифицированных капельных экспресс-методов, а также готовых индикаторных бумаг и тест-систем. СПЭЛ определяет более 20 показателей качества пищи и 12 параметров санитарного состояния (рис. 9).

На основе СПЭЛ разработана войсковая портативная экспресс-лаборатория контроля питания ВПЭЛ-КП для специалистов Госсанэпиднадзора и медицинских служб, которые проводят санитарно-пищевой анализ в полевых условиях, вне стационарных пищевых объектов. Список анализируемых параметров аналогичен СПЭЛ с небольшими отличиями. Методическое обеспечение лаборатории ВПЭЛ-КП утверждено главным военно-медицинским управлением Министерства обороны Российской Федерации.

\section{ПРИМЕНЕНИЕ ПОРТАТИВНОГО \\ ОБОРУДОВАНИЯ В УЧЕБНОМ ПРОЦЕССЕ}

Оборудование 3 АО "Крисмас+" успешно и давно применяется во многих учреждениях систем общего, дополнительного и профессионального образования по всей России для проведения разноуровневых практических занятий в школах, лицеях, гимназиях, вузах. Применение оборудования ЗАО "Крисмас+» предусмотрено учебными программами в проектных и творческих работах по тематикам, связанным с изучением и оценкой состояния окружающей среды, факторов безопасности жизнедеятельности, технологии пищевых продуктов, химико-экологическими и биолого-экологическими исследованиями и т.п. [7]. При этом реализуются практико-ориентированные формы обучения на современном уровне, актуализируется общегуманистическое содержание образования, направленное на сохранение природы, рациональное природопользование, пропаганду здорового образа жизни, безопасность (рис. 10).

Отдельно отметим, что ЗАО "Крисмас+» - ведущая отечественная инновационная компания в области комплексного

\section{ТАТАРСТАНСКИЙ НЕФТЕГАЗОХИМИЧЕСКИЙ}
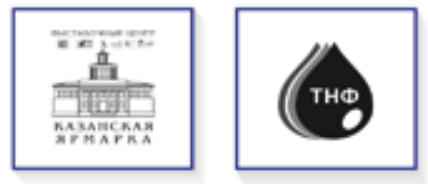
ФOРУM

\section{2-4 сентября 2019, Казань}

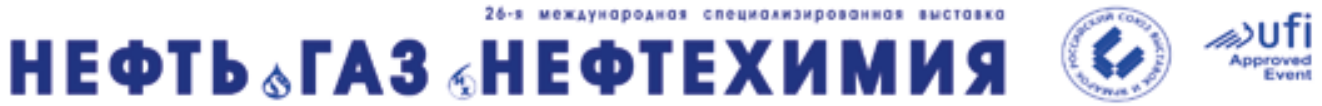

Организаторы:

Правительство Республики Татарстан

ОАО «Казанская ярмарка

При поддержке:

Президента Республики Татарстан

Россия, 420059, г. Казань

Оренбургский тракт, 8

ОАО «Казанская ярмарка

тел.(843) 212-21-44

www.oilexpo.ru, www.expokazan.ru

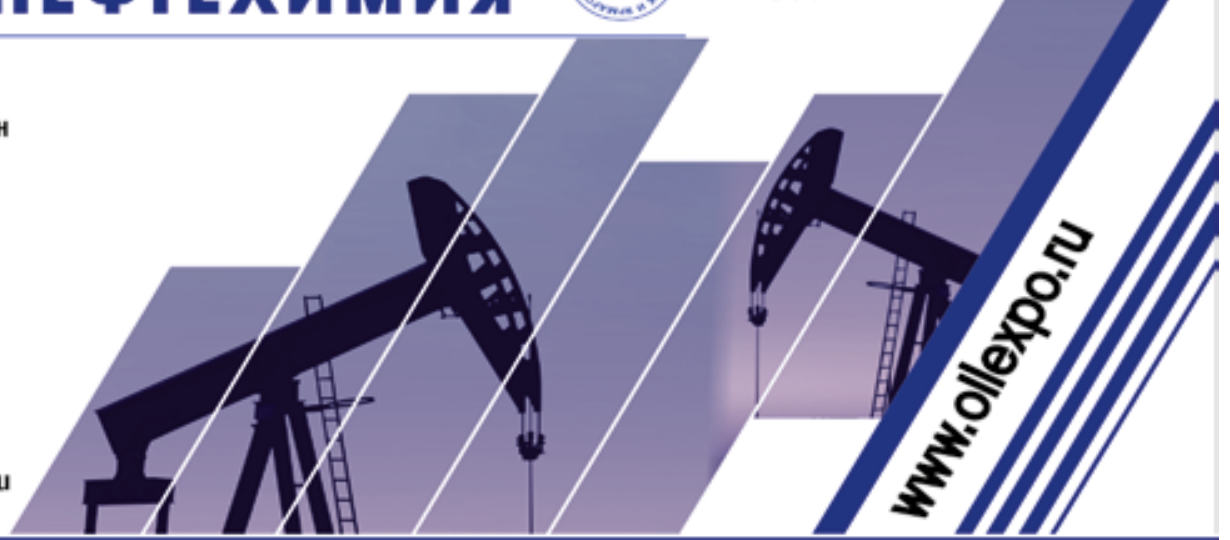


оснащения производственных, научных и учебных лабораторий, которая производит и поставляет практически все для успешной и удобной работы в современных лабораториях. В нашем арсенале широчайший ассортимент оборудования, приборов и средств для химического и физического контроля объектов окружающей среды, а также богатый выбор лабораторной и кабинетной мебели собственного производства. По желанию заказчиков специалисты компании разрабатывают индивидуальные дизайнпроекты мебельного оснащения лабораторных и офисных помещений в едином оригинальном стиле.

Наше предприятие обладает достаточными производственными мощностями, штатом высококвалифицированных специалистов и соответствующим опытом для оснащения современных мобильных лабораторий различного назначения "под ключ».

Компания берет на себя полную ответственность за всю поставляемую продукцию. Если в комплект поставки входит оборудование других производителей, наши специалисты проводят сервисное и гарантийное обслуживание этих приборов в полном объеме.

Все разработанное и производимое ЗАО "Крисмас+» оборудование в обязательном порядке в дополнение к паспортам имеет руководство по применению или инструкцию.

ЗАО «Крисмас+» имеет собственный учебный центр, на базе которого работает региональный специализированный орган по сертификации образовательных услуг, зарегистрированный в реестре системы "Учсерт» Российской академии образования. Прошедшие стажировку в учебном центре специалисты получают навыки эффективной работы с продукцией нашей компании.

В заключение отметим, что тесное взаимодействие ЗАО "Крисмас+» с потребителями создает необходимые предпосылки для широкого применения продукции компании в самых разных областях - от социальной сферы до промышленных и теплоэнергетических предприятий.

\section{ЛИТЕРАТУРА}

1. Муравьёв А., Жохов С. Продукция компании "Крисмас+» - портативные системы для химических экспресс-анализов // АНАЛИТИКА . 2015. № 5. С. 74-81.

2. Петрова Н.М., Муравьев А.Г., Смолев Б. В. и др. Индикаторные трубки и газоопределители. / Под ред. А. Г. Муравьева. - СПб.: "Крисмас+», 2005. 176 с., ил. ISBN: 5-89495-127-5.

3. Руководство по анализу воды. Питьевая и природная вода, почвенные вытяжки / Под ред. к.х.н. А. Г. Муравьёва. - Изд. 4-е, перераб. и дополн.СПб.: "Крисмас+", 2018. 360 с., илл. ISBN978-5-89495-248-2.

4. Водно-химическая экспресс-лаборатория котловая ВХЭЛ. Руководство по применению РП 203-82182574-15 / Составители: А.Г. Муравьев,

В. В.Данилова, Н. А. Осадчая, И. В. Субботина, Е. Б. Кравцова.- СПб.: ЗАО "Крисмас+", 2016. 109 с.

5. Химический анализ почв. Руководство по применению почвенных лабораторий и тест-комплектов / Под ред. к.х.н. А. Г. Муравьёва; изд. 3-е, перераб. и дополн. - СПб.: "Крисмас+", 2015. 136 с., ил ISBN: 978-5-89495-220-8

6. Руководство по санитарно-пищевому анализу с применением тестовых средств / Под ред. к.х.н. А. Г. Муравьёва; изд. 3-е, перераб. СПб.: "Крисмас+», 2018. 144 с. ISBN978-5-89495-242-0.

7. Муравьёв А.Г., Пугал Н. А., Лаврова В.Н.Экологический практикум: Учебное пособие с комплектом карт-инструкций / Под ред. К.х.н. А. Г. Муравьёва; изд. 5-е.- СПб.: «Крисмас+», 2017. 176 с.: ил. ISBN: 978-5-89495-247-5.

8. Руководство к практическим занятиям для лаборатории "Экология и охрана окружающей среды»: Учебное пособие-практикум / Под ред А. Г. Муравьёва; изд. 4-е, исправл. - СПб.: "Крисмас+", 2019. 120 с.

\section{REFERENCES}

1. Muravyov A. G., Zhohov S. Christmas+ Production: Portable Systems for Chemical Express-analysis / Analitika - Analytics, 2015. No. 5. PP. 71-81.

2. Petrova N. M., Muravyov A. G., Smolev B. V., etc. Indicative Tubes and Gas Detectors. Edited by A. G. Muravyov - SPb.: Christmas+, 2005, 176 p., il., ISBN: 5-89495-127-5.

3. Guide on Water Analysis. Drinking and Natural Water, Ground Extracts Edited by A.G. Muravyov. - 4-th Edition. - SPb.: Christmas+, 2018. 360 p., il. ISBN 978-5-89495-248-2.

4. Water and Chemical Boiler Express Laboratory. Guide on RP203-8218257415 Usage. A. G. Muravyov, V. V. Danilova, N. A. Osadchaya, I. V. Subbotina, Ye. B. Kravtsova. SPb.: CJSC Christmas+, 2016. 109 p.

5. Climatic Analysis of Grounds. Guide on Ground Laboratories Usage and Testing Sets. Edited by A. G. Muravyov. 3-rd Edition. SPb.: Christmas+, 2015. 136 p., il. ISBN: 978-5-89495-220-8.

6. Guide on Sanitary and Food Analysis Using Testing Facilities. Edited be A. G. Muravyov. 3-rd Edition. SPb.: Christmas+, 2018. $144 \mathrm{p}$ ISBN 978-5-89495-242-0.

7. Muravyov A. G., Pugal N. A., Lavrova V. N. Ecological Practice: Study Guide with Set of Specification Cards. Edited by A. G. Muravyov. 5-th Edition. SPb.: Christmas+, 2017. 176 p., il. ISBN: 978- 5-89495-247-5.

8. Guide on Practical Trainings for the Laboratory Ecology and Environment Preservation: Study and Practical Guide. Edited by A. G. Muravyov. 4-th Edition. SPb.: Christmas+, 2019. $120 p$ 


\section{(a) (0)}

ПРОИЗВОДСТВО *

KOMПЛЕКСНОЕ ОСНАЩLЕНИЕ

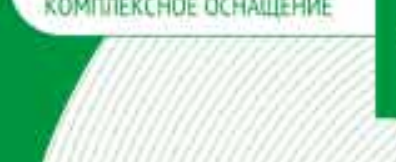

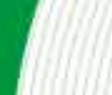

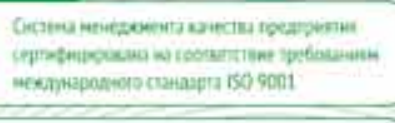

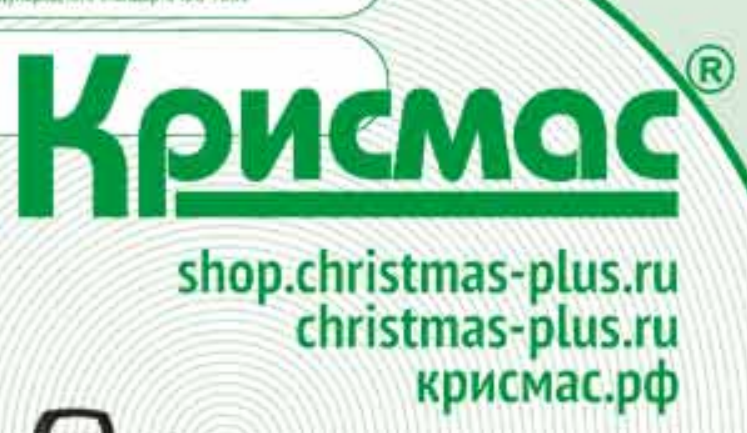

shop.christmas-plus.ru christmas-plus.ru крисмас.рф

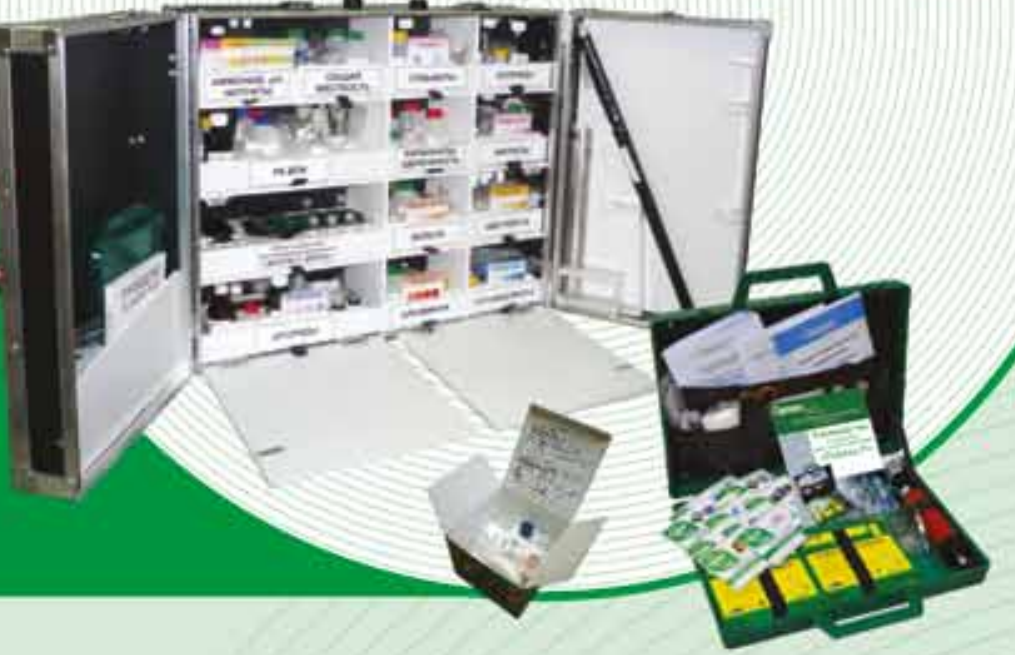

ПРЕИМУЩЕСТВА

ОБОРУДОВАНИЯ, ПРОИЗВОДИМОГО

$3 A 0$ «КРИСМАC+»

простота использования;

портативность, удобство для переноски;

не потребляет электроэнергию;

не требует специального химико-

аналитического образования.

Оборудование экономит время

и существенно уменьшает затраты:

результаты лабораторного контроля

доступны уже через несколько минут

и прямо на месте обследования.

Имеет сертификаты соответствия.

Полностью соответствует требованиям

нормативных документов.

Kpucruac

shop.christmas-plus.ru

\section{Оборудование для газового анализа, анализа воды}

(в том числе котловой), почвы, нефти и нефтепродуктов,

санитарно-пищевого контроля

- Лаборатории химического контроля и разведки

- Судовые лаборатории

- Лабораторное оборудование и приборы

- Передвижные (мобильные) лаборатории

- Лабораторная, офисная мебель

- Нормативно-методические и справочные документы

ГАРАНТИЙНОЕ И ПОСТТАРАНТИЙНОЕ ОБСЛУЖИВАНИЕ

РАССРОЧКА ОПЛАТЫ

МИНИМАЛЬНЫЕ СРОКИ ИЗГОТОВЛЕНИЯ

\section{Уже 25 лет мы проектируем, оснащаем и обслуживаем лаборатории для решения самых различных задач!}

191119 Санкт-Петербург, ул. Константина Заспонова, дом 6 Ten./фakc: (812) 575-50-81, 575-55-43, 575-54-07,575-57-91

8 (800) 302-92-25 - звонок по России бесплатный

Факс: (812) 325-34-79

E-mail: info@christmas-plus.ru

Сайты: shop.christmas-plus.ru, christmas-plus.ru, крисмас.pф. center-souz.ru
Офис продаж в Москве:

127247 Москва,

Дмитровское шоссе, А. 96, корп. 2

Ten.: (917) 579-66-02

E·mail: n-chernyh@christmas.plus.ru

Сайr: ecologlab,ru 